\title{
BMJ Open COVID-19 outbreak-related psychological distress among healthcare trainees: a cross-sectional study in China
}

\author{
Yue Wang, ${ }^{1}$ Yuchen $\mathrm{Li},{ }^{1,2}$ Jingwen Jiang, ${ }^{2}$ Yuying Feng, ${ }^{3}$ Donghao Lu (D) , ${ }^{4,5}$ \\ Wei Zhang (D) , ${ }^{1,2}$ Huan Song ${ }^{2,6}$
}

To cite: Wang Y, Li Y, Jiang J, et al. COVID-19 outbreakrelated psychological distress among healthcare trainees: a cross-sectional study in China. BMJ Open 2020;10:e041671. doi:10.1136/ bmjopen-2020-041671

- Prepublication history and additional material for this paper are available online. To view these files, please visit the journal online (http://dx.doi. org/10.1136/bmjopen-2020041671).

YW and YL contributed equally.

Received 16 June 2020

Revised 01 September 2020

Accepted 08 October 2020
Check for updates

(C) Author(s) (or their employer(s)) 2020. Re-use permitted under CC BY. Published by BMJ.

For numbered affiliations see end of article.

\section{Correspondence to} Dr Donghao Lu; donghao.lu@ki.se and Professor Wei Zhang; weizhanghx@163.com

\section{ABSTRACT}

Objectives The COVID-19 outbreak has caused enormous strain on healthcare systems, and healthcare trainees, which comprise the future healthcare workforce, may be a vulnerable group. It is essential to assess the psychological distress experienced by healthcare trainees during the COVID-19 outbreak.

Design, setting and participants A cross-sectional study with 4184 healthcare trainees at Sichuan University in China was implemented during 7-13 February 2020. Participants were grouped by training programmes (medicine, medical technology and nursing) and training stages (undergraduate, postgraduate and residency). Main outcomes COVID-19-related psychological distress and acute stress reaction (ASR) were assessed using the Kessler 6-item Psychological Distress Scale and the Impact of Event Scale-Revised, respectively. We estimated the ORs of distress by comparing trainees across programmes and training stages using multivariable logistic regression.

Results Significant psychological distress was found in $1150(30.90 \%)$ participants and probable ASR in 403 $(10.74 \%)$. Compared with the nursing trainees, the medical trainees (OR 1.54, 95\% $\mathrm{Cl} 1.22$ to 1.95 ) reported a higher burden of psychological distress during the outbreak, while the medical technology trainees (OR 1.25, 95\% Cl 0.97 to 1.62 ) reported similar symptom scores. Postgraduates (OR $1.55,95 \% \mathrm{Cl} 1.16$ to 2.08 ) in medicine had higher levels of distress than their undergraduate counterparts did, whereas the nursing residents (OR $0.38,95 \% \mathrm{Cl}$ 0.20 to 0.71 ) reported a lower burden than did nursing undergraduates. A positive association was found between having active clinical duties during the outbreak and distress (OR 1.17, 95\% $\mathrm{Cl} 0.98$ to 1.39), particularly among the medical trainees $(\mathrm{OR} 1.85,95 \% \mathrm{Cl} 1.47$ to 2.33$)$ and undergraduates (OR $4.20,95 \% \mathrm{Cl} 1.61$ to 11.70 ). No clear risk patterns of ASR symptoms were observed.

Conclusions Medical trainees, particularly postgraduates and those with active clinical duties, were at risk for psychological distress during the COVID-19 outbreak. Stress management may be considered for high-risk healthcare trainees.

\section{INTRODUCTION}

The ongoing global pandemic of the 2019 novel coronavirus disease (COVID-19) has caused 1991562 cases and 130885 deaths

\section{Strengths and limitations of this study}

- We assessed psychological distress among healthcare trainees across different programmes and training stages during the COVID-19 outbreak.

- To shed light on the pandemic's impact on trainees' lives and work, we assessed their concerns and needs during the outbreak and their influence on the future career choices of the trainees without active clinical duties; we also evaluated work-family conflict and support among trainees with clinical duties.

- Our analyses were limited by the study's crosssectional design, its setting in a single medical school and teaching hospital; hence, the results should be interpreted in light of these limitations and the survey's constraints.

as of 16 April 2020. ${ }^{1}$ Witnessing an unexpected illness or death, fear of being in direct contact with and infected by patients with COVID-19, and dealing with household financial hardships during the outbreak have increased the mental burden in the general population. ${ }^{2}$ These factors have also elevated the mental burden of healthcare trainees and workers, ${ }^{3-5}$ with frontline workers having heavy workloads and being placed at higher risk for COVID-19, due to the drastic surge in patients with COVID-19. Emerging data indicate that Chinese healthcare workers exposed to COVID-19 have experienced psychological symptoms, especially women, nurses, those in Wuhan (the first epicentre) and frontline workers. ${ }^{6}$ Other studies have reported a profound mental impact of the COVID-19 outbreak on healthcare workers globally. ${ }^{357}$

Despite their limited direct contact with patients with COVID-19, healthcare trainees are a vulnerable group. ${ }^{8}$ As the pandemic escalates, many countries are considering or have already graduated senior students earlier to assist frontline workers. Other aggressive approaches have been proposed, for instance, suspending all medical school 
education for 1 year and recruiting medical students tor testing, tracking and quarantining patients with COVID19. ${ }^{9}$ Although many trainees are inspired during these unprecedented times, some, especially those without sufficient clinical experience, may experience stress. Nevertheless, the psychological state of healthcare trainees across various programmes and training stages, in response to the COVID-19 outbreak, is unknown.

\section{MATERIALS AND METHODS \\ Study design}

We conducted a cross-sectional study of healthcare trainees from the West China School of Medicine and West China Hospital, Sichuan University during 7-13 February 2020. We invited 7177 individuals, including 2483 undergraduates, 2606 postgraduates and 2088 residents, to participate in this study to assess their mental health and working conditions during the COVID-19 outbreak via WeChat, a popular social media application in China. The 4184 trainees who agreed to participate were included in the analyses. For data protection, answers to these electronic questionnaires were kept anonymously. The response rates for undergraduates, postgraduates and residents were $73.22 \%, 71.49 \%$ and $24.09 \%$, respectively (online supplemental figure 1 ).

We focused exclusively on the main concerns and needs of undergraduates and postgraduates who were not involved in clinical work during the COVID-19 epidemic, and the impact of their experiences on their future career plans. We also conducted a short survey of clinical workers about work-family conflict and support during the epidemic. The total number of participants included 1818 undergraduates, 1863 postgraduates and 503 residents.

Most of the undergraduate and postgraduate students were at home throughout the country during the COVID-19 outbreak due to the Chinese Spring Festival, while all residents remained in Chengdu, Sichuan Province because of their clinical duties. As of 6 February 2020, the total number of confirmed COVID-19 cases was 344 in Sichuan Province (102 in Chengdu), and 7226 individuals were under medical observation. ${ }^{10}$

\section{Healthcare programmes and training stages}

Healthcare training programmes in China mainly consist of medicine, medical technology and nursing for the preparation of future doctors, medical technologists (including medical laboratory technologists, imaging technologists, physical therapists and optometrists) and nurses to practice in healthcare settings. The training stages in this study were divided into three categories: undergraduate, postgraduate and residency. All training programmes begin during students' enrolment in undergraduate programmes; the length of training of medical programmes is 5 years, and it is 4 years for medical technology and nursing programmes. After graduation, individuals continue training in a postgraduate programme
(3-6 years) with a primary focus on research, which can be combined with clinical training. Students who pursue careers as clinicians enter a residency programme (3 years for medicine and 2 years for medical technology and nursing) for supervised clinical practice after graduation from an undergraduate or postgraduate programme.

Due to the co-occurrence of COVID-19 and the Chinese Spring Festival, individuals in the early stage of training had a low proportion of clinical experiences at the time of the survey. In order to protect students without clinical experience, the medical school cancelled clinical practicums for undergraduates after the COVID-19 outbreak, and a few of the senior undergraduates with internship experiences volunteered to remain at the hospital and support its clinical work. The clinically active trainees included 503 residents and 325 students (304 postgraduates and 21 undergraduates). To assess the work status of the trainees, we asked all participants in the survey, "Are you actively performing clinical duties at this time?" (online supplemental text).

\section{Assessment of outbreak-related psychological distress}

When we assessed psychological distress and acute stress reaction (ASR), we phrased the questions so they were specific to the COVID-19 outbreak (online supplemental text).

Psychological distress was assessed using the Chinese version of the Kessler Psychological Distress Scale (K6). The instrument consists of six items pertaining to major depression and generalised anxiety disorder and asks respondents how frequently they have experienced relevant symptoms during the past month. ${ }^{11}$ Each item has five options ranging from 0 (never) to 4 (all of the time), and the total score ranges from 0 to 24 . We considered a score $\geq 5$ as clinically significant distress in accordance with the validation studies on Asian populations. ${ }^{12} 13$ Cronbach's alpha was 0.91 in our study, indicating good scale reliability.

The variable ASR was evaluated using the Chinese version of the Impact of Event Scale-Revised (ISE-R). ${ }^{14}$ The instrument consists of 22 items and yields a total score and scores on the Intrusion, Avoidance and Hyperarousal subscales. Respondents identify a stressful event and how much they were distressed or bothered during the past 7 days by the difficulties listed in the items. Responses are rated on a 5-point scale, ranging from 0 (not at all) to 4 (extremely). Individuals with a score $\geq 24$ points are considered to have probable ASR. ${ }^{15} 16$ Cronbach's $\alpha$ was 0.91 in our study, suggesting good scale reliability.

\section{Assessment of the outbreak's impact}

To shed light on the impact of the outbreak on trainees' lives and work, we assessed the concerns and needs of trainees without active clinical duties during the outbreak and the pandemic's influence on their future career choices. We also evaluated work-family conflict and support among the trainees with clinical duties (online supplemental text). 
Concerns and needs during the outbreak, and their influence on future career choices: To understand trainees' main concerns and needs, we asked the following question. "Under the current circumstances, I am concerned about a) being infected with the novel coronavirus; b) my physical health condition; c) my psychological health; d) academic performance; e) my social life and work; f) my traveling plans; g) the risk of infection from family members or friends; h) my personal and family's financial situation; and i) other issues." We also asked participants to respond to the following item. "If I were to work during the outbreak, I would need: a) personal protective equipment; b) social insurance; c) salary incentives; d) clinical practice guidance; e) professional track record; and f) other needs." Multiple responses were allowed for these questions. We used one single question: "Has the outbreak affected your future career plans?" to assess the impact of the COVID-19 outbreak on trainees' future career plans.

Work-family conflict and support: The 9-item Chinese version of the Work-Family Conflict and Support Scale was used to investigate work-family conflict, social support and policy support. ${ }^{17}$ Each dimension has three items and each item has three options: 1 (agree), 2 (neutral) and 3 (disagree).

\section{Statistical analysis}

We compared the baseline characteristics of the trainees across the different programmes (ie, medicine, medical technology and nursing) using Student's t-test (for continuous variables) and the $\chi^{2}$ test (for categorical variables). We described the distributions of the symptoms' scores (transformed z-scores are reported as mean SD), and the proportion of identified cases (corresponding to the cut-off points stated in the Methods section), in each of the three programme groups. Differences in symptom scores or the probability of cases were estimated using linear regression ( $\beta$ coefficients) and logistic regression (ORs), respectively. We examined the associations of the concerns, needs and future career choices with psychological distress and ASR among the participants without active clinical duties, and the associations of family-work conflict with psychological distress and ASR in the participants with active clinical duties. All models were adjusted for age, sex, marital status and epidemic contact characteristics to address confounding by these variables. We also adjusted the model for training programme and training stage when analysing the associations of concerns, needs, career impact and family-work conflicts with psychological distress and ASR. As the status of clinical duty is strongly correlated with training stage, we did not adjust for active clinical duty (yes or no) as covariates. Individuals with missing data on the measures of psychological distress $(462,11.04 \%)$ or ASR $(433,10.35 \%)$ were not included in the corresponding analyses. We analysed the data anonymously, and all analyses were conducted using R V.3.6.1; $p$ value $<0.05$ was considered to be statistically significant.

\section{Patient and public involvement}

Patients and/or the public were not involved in the design, or conduct, or reporting, or dissemination plans of this research.

\section{RESULTS \\ Demographic characteristics}

The mean age of the 4184 participants was $23.41 \pm 3.81$ years and $64.89 \%$ were females. No confirmed cases of COVID-19 were reported, but $31(0.74 \%)$ trainees had at least one relative who was infected. Approximately onefifth $(19.79 \%)$ of participants were involved in active clinical duties; among them, $74(8.94 \%)$ were working on the front lines and $38(4.59 \%)$ had direct contact with patients with COVID-19 (table 1). Compared with trainees in the medical technology and nursing programmes, the trainees in medicine were older $(p<0.01)$ and more likely to be postgraduates $(\mathrm{p}<0.01)$, males $(\mathrm{p}<0.01)$, married $(\mathrm{p}<0.01)$ and living outside of Hubei Province, the first epicentre $(p=0.02)$. At the time of the survey, nursing trainees were more likely to have active clinical duties and work on the front lines $(\mathrm{p}<0.01)$.

\section{Outbreak-related psychological distress and ARS}

During the outbreak, $1150(30.90 \%)$ trainees reported significant psychological distress and 403 (10.74\%) reported probable ASR. Distress symptoms ( $\beta$ 0.24, $95 \%$ CI 0.14 to 0.35 ) and cases of significant distress (OR $1.54,95 \%$ CI 1.22 to 1.95 ; table 2 ) were positively associated with being medical trainees, compared with being nursing trainees. A similar pattern was found among medical technology trainees $(\beta 0.13,95 \%$ CI 0.02 to 0.25 ; OR $1.25,95 \%$ CI 0.97 to 1.62 ), although the association with distress cases was not significant. Compared with undergraduates, postgraduates (OR 1.55, 95\% CI 1.16 to 2.08) in the medical programme had higher levels of distress, whereas nursing residents (OR $0.38,95 \%$ CI 0.20 to 0.71 ) reported a lower burden. No significant increase was found across training stages among the medicaltechnology trainees. Similar patterns, with weaker associations, were observed for symptoms of ASR and probable distress cases across the training programmes and stages within the programmes, except for the lower burden of ASR symptoms reported by the medical residents compared with the undergraduates.

Associations of active clinical duties during the outbreak with distress symptoms ( $\beta 0.09,95 \%$ CI 0.01 to 0.18$)$ and cases of significant distress (OR 1.17, $95 \%$ CI 0.98 to 1.39 ; table 3 ) were found. The association between active duties and distress was positive among the medical trainees (OR $1.85,95 \%$ CI 1.47 to 2.33), but negative among the nursing trainees (OR $0.55,95 \%$ CI 0.32 to 0.93 ). The association was slightly stronger among undergraduates (OR $4.20,95 \%$ CI 1.61 to 11.70$)$ than it was among postgraduates (OR 2.23, 95\% CI 1.72 to 2.91). However, active clinical duty was negatively associated with ASR symptoms ( $\beta$ $-0.10,95 \% \mathrm{CI}-0.19$ to -0.02$)$, and except for that finding, 
Table 1 Characteristics of healthcare trainees $-\mathrm{N}(\%)$ or mean (SD)

\begin{tabular}{|c|c|c|c|c|c|}
\hline & All & Medicine & Medical technology & Nursing & $P$ value \\
\hline Participants, N & 4184 & $2727(65.18)$ & $944(22.56)$ & $513(12.26)$ & \\
\hline Age, years, mean (SD) & $23.41(3.81)$ & $24.20(3.84)$ & $21.90(3.24)$ & $21.98(3.36)$ & $<0.01$ \\
\hline Sex & & & & & $<0.01$ \\
\hline Male & $1469(35.11)$ & $1133(41.55)$ & $265(28.07)$ & $71(13.84)$ & \\
\hline Female & $2715(64.89)$ & $1594(58.45)$ & $679(71.93)$ & $442(86.16)$ & \\
\hline Marital status & & & & & $<0.01$ \\
\hline Married & $331(7.91)$ & $254(9.31)$ & $48(5.08)$ & $29(5.65)$ & \\
\hline Unmarried & $3853(92.09)$ & $2473(90.69)$ & 896 (94.92) & $484(94.35)$ & \\
\hline Training stage & & & & & $<0.01$ \\
\hline Undergraduate & $1791(42.81)$ & $940(34.47)$ & $588(62.29)$ & $263(51.27)$ & \\
\hline Postgraduate & $1890(45.17)$ & $1662(60.95)$ & $142(15.04)$ & $86(16.76)$ & \\
\hline Residency & $503(12.02)$ & $125(4.58)$ & $214(22.67)$ & $164(31.97)$ & \\
\hline Location & & & & & 0.02 \\
\hline Hubei $^{\star}$ & $67(1.60)$ & $46(1.69)$ & $20(2.12)$ & $1(0.19)$ & \\
\hline Outside Hubei & $4117(98.40)$ & 2681 (98.31) & $924(97.88)$ & $512(99.81)$ & \\
\hline Relatives with COVID-19 & & & & & 0.90 \\
\hline No & $4153(99.26)$ & $2706(99.23)$ & $937(99.26)$ & $510(99.42)$ & \\
\hline Yes & $31(0.74)$ & $21(0.77)$ & $7(0.74)$ & $3(0.58)$ & \\
\hline Active clinical duty & & & & & $<0.01$ \\
\hline No & $3356(80.21)$ & 2301 (84.38) & $719(76.17)$ & $336(65.50)$ & \\
\hline Yes & $828(19.79)$ & $426(15.62)$ & $225(23.83)$ & $177(34.50)$ & \\
\hline Working position† & & & & & $<0.01$ \\
\hline Frontlineł & $74(8.94)$ & $36(8.54)$ & $5(2.22)$ & $33(18.64)$ & \\
\hline Second-line & 754 (91.06) & $390(91.55)$ & $220(97.78)$ & $144(81.36)$ & \\
\hline Contact with COVID-19† & & & & & 0.11 \\
\hline Yes & $38(4.59)$ & $24(5.63)$ & $11(4.89)$ & $3(1.69)$ & \\
\hline No & $790(95.41)$ & $402(94.37)$ & $214(95.11)$ & $174(98.31)$ & \\
\hline
\end{tabular}

*Hubei Province was the epicentre at the time of the survey.

†Information was only assessed for participants with activity clinical duty.

‡Frontline working positions was defined as working in departments directly engaging in care for patients with COVID-19, including Emergency, Respiratory, Critical Care Medicine and Infectious Disease Departments.

almost all associations of ASR across training programmes and stages were not significant.

\section{Outbreak's impact on vulnerable trainees}

Among the trainees without active clinical duties during the outbreak, psychological distress was significantly associated with concerns about mental health (OR 2.41, 95\% CI 1.90 to 3.04; table 4) and demands for personal protective equipment (OR 1.51, 95\% CI 1.07 to 2.16). They were more likely to consider future careers outside of medicine (OR 2.89, 95\% CI 1.77 to 4.69). A similar pattern was found for ASR, except for concerns about academic performance, travel plans, personal or family financial hardship, and the need for personal protective equipment, which were only associated with psychological distress.
Among the trainees with active clinical duties, those with distress were more likely to report work-family conflict (ORs 2.20-2.68; table 5). In contrast, adequate social support (ORs $0.42-0.47$ ) and reasonable work arrangements (ORs 0.40-0.47) were associated with lower psychological distress. A similar pattern was found for ASR.

\section{DISCUSSION}

In this large-scale cross-sectional study, we found that psychological distress was common among healthcare trainees during the COVID-19 outbreak. Medical trainees, particularly postgraduates and those with active clinical duties, were at higher risk for psychological distress, compared with those in other training programmes or at 


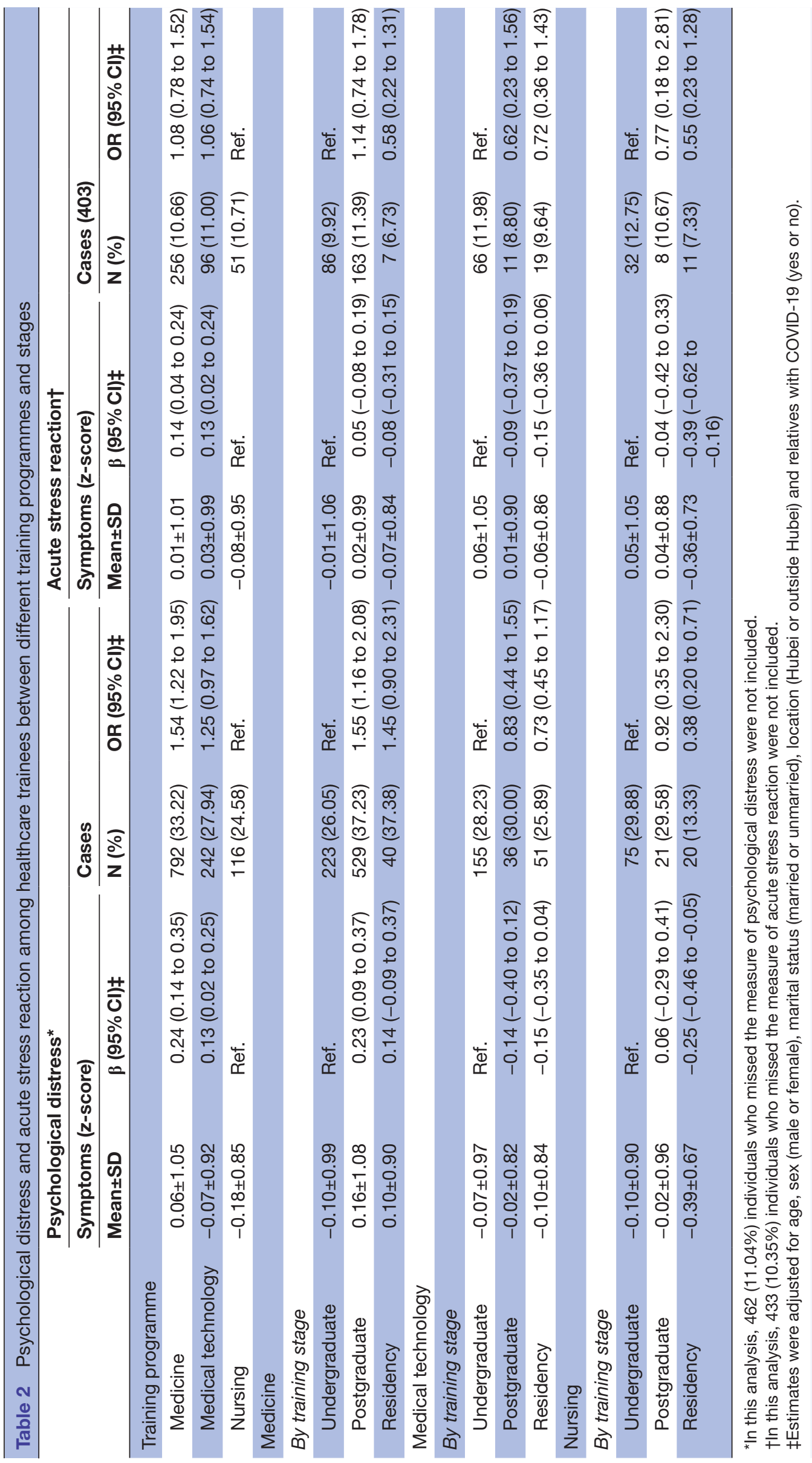




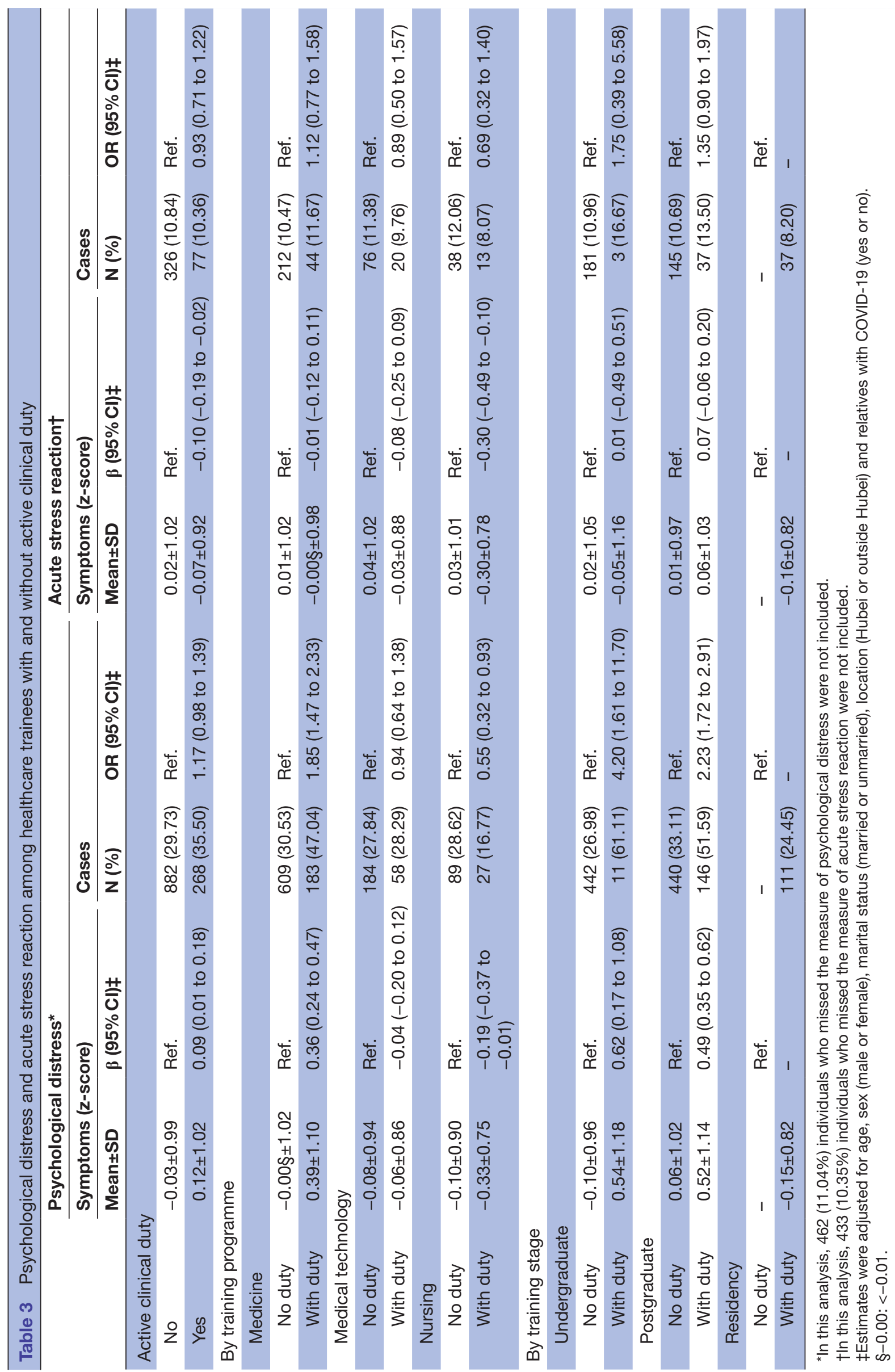


Table 4 Associations of concerns and needs during COVID-19 outbreaks with psychological distress and acute stress reaction among healthcare trainees without active clinical duty

\begin{tabular}{|c|c|c|c|c|c|c|}
\hline & \multicolumn{3}{|c|}{ Psychological distress* } & \multicolumn{3}{|c|}{ Acute stress reaction $\dagger$} \\
\hline & \multirow{2}{*}{$\begin{array}{l}\text { No }(n=2085) \\
N(\%)\end{array}$} & \multirow{2}{*}{$\begin{array}{l}\text { Yes (n=882) } \\
N(\%)\end{array}$} & \multirow[b]{2}{*}{ OR (95\% Cl)‡ } & \multirow{2}{*}{$\begin{array}{l}\text { No }(n=2682) \\
N(\%)\end{array}$} & \multirow{2}{*}{$\begin{array}{l}\text { Yes }(n=326) \\
N(\%)\end{array}$} & \multirow[b]{2}{*}{ OR (95\% Cl)‡ } \\
\hline & & & & & & \\
\hline $\begin{array}{l}\text { Being infected with the novel } \\
\text { coronavirus }\end{array}$ & $1298(66.84)$ & $644(33.16)$ & 1.33 (1.09 to 1.61$)$ & $1713(87.00)$ & $256(13.00)$ & 1.42 (1.05 to 1.95$)$ \\
\hline Physical health condition & $458(59.17)$ & $316(40.83)$ & 1.41 (1.16 to 1.72$)$ & $630(80.36)$ & $154(19.64)$ & 1.81 (1.37 to 2.39$)$ \\
\hline Academic performance & $1195(66.24)$ & 609 (33.76) & 1.30 (1.09 to 1.56$)$ & $1606(87.95)$ & $220(12.05)$ & $0.97(0.74$ to 1.27$)$ \\
\hline Social life and work & $383(64.37)$ & $212(35.63)$ & 1.19 (0.95 to 1.48$)$ & 505 (83.61) & 99 (16.39) & $1.38(1.01$ to 1.87$)$ \\
\hline Travelling plans & $141(58.02)$ & $102(41.98)$ & 1.36 (1.01 to 1.82$)$ & $201(81.38)$ & $46(18.62)$ & 1.220 .81 to 1.79 ) \\
\hline $\begin{array}{l}\text { Family members or friends } \\
\text { being infected with the novel } \\
\text { coronavirus }\end{array}$ & $1297(68.41)$ & 599 (31.59) & 0.94 (0.78 to 1.13$)$ & $1688(87.96)$ & $231(12.04)$ & 0.91 (0.69 to 1.21$)$ \\
\hline \multicolumn{7}{|l|}{ Needs } \\
\hline Personal protective equipment & $1907(69.50)$ & $837(30.50)$ & 1.51 (1.07 to 2.16$)$ & $2485(89.26)$ & $299(10.74)$ & 0.74 (0.48 to 1.18$)$ \\
\hline Social insurance & $1819(69.24)$ & $808(30.76)$ & 1.31 (0.98 to 1.76$)$ & 2371 (89.03) & $292(10.97)$ & 0.86 (0.58 to 1.32$)$ \\
\hline Salary incentives & $1386(68.21)$ & $646(31.79)$ & 1.37 (1.12 to 1.67$)$ & $1809(87.69)$ & $254(12.31)$ & 1.79 (1.32 to 2.44$)$ \\
\hline Clinical practice guidance & $1317(70.58)$ & $549(29.42)$ & 0.89 (0.73 to 1.08$)$ & $1672(88.42)$ & $219(11.58)$ & 1.13 (0.85 to 1.50$)$ \\
\hline Professional track record & $1213(70.16)$ & $516(29.84)$ & 0.91 (0.75 to 1.11$)$ & $1551(88.63)$ & $199(11.37)$ & 0.92 (0.69 to 1.23$)$ \\
\hline \multicolumn{7}{|l|}{ Future career choice } \\
\hline Healthcare worker & $1256(73.80)$ & $446(26.20)$ & Ref. & 1587 (91.89) & $140(8.11)$ & Ref. \\
\hline $\begin{array}{l}\text { Medicine related-but not } \\
\text { bedside }\end{array}$ & $618(69.52)$ & $271(30.84)$ & 1.26 (1.05 to 1.52$)$ & $791(87.89)$ & $109(12.11)$ & 1.54 (1.17 to 2.02$)$ \\
\hline
\end{tabular}

*In this analysis, 389 (11.59\%) individuals who missed the measure of psychological distress were not included.

†In this analysis, $348(10.37 \%)$ individuals who missed the measure of acute stress reaction were not included.

łEstimates were adjusted for age, sex (male or female), marital status (married or unmarried), location (Hubei or outside Hubei), relatives with

COVID-19 (yes or no), training programmes (medicine, medical technology or nursing) and training stage (undergraduate, postgraduate or residency).

an earlier training stage. Concerns about mental health were strongly correlated with psychological distress among trainees with no clinical duties, whereas workfamily conflict was the greatest concern of distressed trainees with active clinical duties.

The strain of COVID-19 on healthcare systems, medical trainees and other practitioners is challenging. Consistent with prior research, ${ }^{6} 1819$ our results indicated that psychological distress was common among healthcare trainees, especially those in medical training programmes. Conversely, several studies reported that nurses providing care for confirmed or suspected COVID-19 cases had a greater mental burden than doctors. ${ }^{6}{ }^{20}$ Given the small proportion of participants $(4.59 \%)$ who had direct contact with infected patients, these inconsistent estimates do not invalidate each other.

Another important finding was the association of being in the advanced training stage and having active clinical duties with higher levels of psychological distress. Academic pressures, workload and financial burden increase with level of training, which could, consequently, increase the mental vulnerability of senior trainees and ultimately contribute to negative mental outcomes. ${ }^{21-25}$ During the COVID-19 outbreak, senior medical students and residents were encouraged to assist hospital staff with clinical work to deal with the severe workforce shortage. ${ }^{26} 27$ The overwhelming workload and high risk of exposure to COVID-19 might have added to their mental burden. We consistently observed a higher risk of psychological distress across all training stages among individuals who were involved in active clinical duties during the outbreak.

ASR often develops following direct exposure to traumatic events, such as experiencing the COVID-19 outbreak in the epicentre and being charged with the direct care (diagnosis and treatment) of patients confirmed with COVID-19. ${ }^{6}{ }^{28}$ However, few participants were quarantined in the epicentre or had direct contact with infected patients at the time of the survey. The risk for ASR was relatively low and differences between the 
Table 5 Associations of family-work conflicts during COVID-19 outbreak with psychological distress and acute stress reaction among healthcare trainees with active clinical duty

\begin{tabular}{|c|c|c|c|c|}
\hline \multicolumn{2}{|c|}{ Psychological distress* } & & \multicolumn{2}{|c|}{ Acute stress reaction $\dagger$} \\
\hline No $(n=487)$ & Yes $(n=268)$ & & No $(n=666)$ & Yes $(n=77)$ \\
\hline N (\%) & $\mathrm{N}(\%)$ & OR $(95 \% \mathrm{Cl}) \neq$ & $\mathrm{N}(\%)$ & $N(\%)$ \\
\hline
\end{tabular}

Work-family conflict

Difficult to care for family due to work

\begin{tabular}{|c|c|c|c|c|c|c|}
\hline Agree & $122(18.32)$ & $28(36.36)$ & 2.53 (1.67 to 3.84$)$ & $59(12.11)$ & $93(34.70)$ & 1.86 (1.06 to 3.22$)$ \\
\hline Neutral & $331(49.70)$ & $42(54.55)$ & Ref. & $249(5.13)$ & $135(50.37)$ & Ref. \\
\hline Disagree & $213(31.98)$ & 7 (9.09) & 0.47 (0.31 to 0.72$)$ & $179(36.76)$ & 40 (14.93) & 0.25 (0.10 to 0.55$)$ \\
\hline \multicolumn{7}{|c|}{ Family responsibilities affected work } \\
\hline Agree & $37(5.56)$ & $14(18.18)$ & 2.20 (1.16 to 4.29$)$ & $19(3.90)$ & $33(12.31)$ & 2.56 (1.22 to 5.20$)$ \\
\hline Neutral & 265 (39.79) & $44(57.14)$ & Ref. & $172(35.32)$ & $145(54.10)$ & Ref. \\
\hline Disagree & $364(54.65)$ & $19(24.88)$ & 0.39 (0.28 to 0.56$)$ & $296(60.78)$ & $90(33.58)$ & 0.31 (0.17 to 0.54$)$ \\
\hline \multicolumn{7}{|c|}{ Difficulties in juggling work and family } \\
\hline Agree & $36(5.41)$ & $14(18.18)$ & 2.68 (1.35 to 5.56$)$ & $14(2.87)$ & $37(13.81)$ & 2.44 (1.13 to 5.12$)$ \\
\hline Neutral & $246(36.94)$ & $43(55.84)$ & Ref. & $155(31.83)$ & $140(52.24)$ & Ref. \\
\hline Disagree & $384(57.66)$ & $20(25.97)$ & 0.37 (0.26 to 0.53$)$ & $318(65.30)$ & $91(33.96)$ & 0.28 (0.15 to 0.50$)$ \\
\hline \multicolumn{7}{|c|}{ Social support } \\
\hline \multicolumn{7}{|c|}{ Support from family } \\
\hline Agree & $466(69.97)$ & $35(45.45)$ & 0.47 (0.33 to 0.67$)$ & $359(73.72)$ & $148(55.22)$ & 0.41 (0.24 to 0.71$)$ \\
\hline Neutral & $166(24.92)$ & $31(40.26)$ & Ref. & $107(21.97)$ & $95(35.45)$ & Ref. \\
\hline Disagree & $34(5.11)$ & $11(14.29)$ & 1.16 (0.59 to 2.33$)$ & $21(4.31)$ & $25(9.33)$ & 1.62 (0.70 to 3.55$)$ \\
\hline \multicolumn{7}{|c|}{ Support from colleagues } \\
\hline Agree & $545(81.83)$ & $44(57.14)$ & $0.42(0.28$ to 0.63$)$ & $414(85.01)$ & $181(67.54)$ & 0.32 (0.19 to 0.55$)$ \\
\hline Neutral & $110(16.52)$ & $30(38.96)$ & Ref. & 65 (13.35) & $81(30.22)$ & Ref. \\
\hline Disagree & $11(1.65)$ & $3(3.90)$ & $0.51(0.15$ to 1.70$)$ & $8(1.64)$ & $6(2.24)$ & 0.99 (0.21 to 3.57$)$ \\
\hline \multicolumn{7}{|c|}{ Support from supervisors } \\
\hline Agree & $505(75.83)$ & $30(38.96)$ & $0.42(0.29$ to 0.60$)$ & $389(79.98)$ & $150(55.97)$ & 0.22 (0.13 to 0.38$)$ \\
\hline Neutral & $146(21.92)$ & $39(50.65)$ & Ref. & 87 (17.86) & 105 (39.18) & Ref. \\
\hline Disagree & $15(2.25)$ & $8(10.39)$ & $0.86(0.35$ to 2.14$)$ & $11(2.26)$ & $13(4.85)$ & 2.32 (0.85 to 6.04$)$ \\
\hline
\end{tabular}

Policy support

Reasonable holiday arrangement

\begin{tabular}{|c|c|c|c|c|c|c|}
\hline Agree & $463(69.52)$ & 28 (36.36) & 0.44 (0.30 to 0.65$)$ & $369(75.77)$ & $126(47.01)$ & 0.27 (0.15 to 0.48$)$ \\
\hline Neutral & 156 (23.42) & $34(44.16)$ & Ref. & $94(19.30)$ & $102(38.06)$ & Ref. \\
\hline Disagree & $47(7.06)$ & 15 (19.48) & 1.32 (0.72 to 2.44$)$ & $24(4.93)$ & $40(14.93)$ & 1.51 (0.72 to 3.07$)$ \\
\hline \multicolumn{7}{|c|}{ Reasonable duty arrangement } \\
\hline Agree & 468 (70.27) & $29(37.66)$ & $0.47(0.32$ to 0.68$)$ & 371 (76.18) & $129(48.13)$ & 0.27 (0.15 to 0.47$)$ \\
\hline Neutral & $163(24.47)$ & 37 (48.05) & Ref. & $100(20.53)$ & 106 (39.55) & Ref. \\
\hline Disagree & $35(5.26)$ & $11(14.29)$ & 1.69 (0.86 to 3.40$)$ & $16(3.29)$ & 33 (12.31) & 1.27 (0.56 to 2.73$)$ \\
\hline
\end{tabular}

Flexible policies to balance family and work

$\begin{array}{lcclccl}\text { Agree } & 438(65.77) & 25(32.47) & 0.40(0.28 \text { to } 0.58) & 356(73.10) & 109(40.67) & 0.29(0.16 \text { to } 0.52) \\ \text { Neutral } & 200(30.03) & 36(46.75) & \text { Ref. } & 120(24.64) & 123(45.90) & \text { Ref. } \\ \text { Disagree } & 28(4.20) & 16(20.78) & 3.09(1.52 \text { to } 6.74) & 11(2.26) & 36(13.43) & 3.47(1.63 \text { to } 7.24)\end{array}$

*In this analysis, 73 (8.82\%) individuals who missed the measure of psychological distress were not included. †In this analysis, $85(10.27 \%)$ individuals who missed the measure of acute stress reaction were not included. łEstimates were adjusted for age, sex (male or female), marital status (married or unmarried), relatives with COVID-19 (yes or no), working position (frontline or second-line), contact with COVID-19 (yes or no), training programmes (medicine, medical technology or nursing) and training stage (undergraduate, postgraduate or residency). 
training programmes and stages were small. Interestingly, we found that trainees with active clinical duties had fewer ASR symptoms during the outbreak.

Our findings suggest that being infected by COVID-19 was the healthcare trainees' leading concern, followed by concerns about their mental health, with regards to psychological distress and ASR. Adequate personal protective equipment and salary incentives might help reduce psychological distress, which is consistent with the finding that family-income stability is a protective factor against anxiety among medical students. ${ }^{29}$ Among clinical workers, work-family conflict was positively associated with psychological distress and negatively associated with social support. Therefore, adequate personal protection, timely psychological interventions, a stable financial situation, a strong family and social support may be key factors in reducing the risk of psychological distress among healthcare trainees. Competent leadership, including active participation in outbreak preparedness and making reasonable work arrangements, could also alleviate the emotional strain on healthcare trainees, suggesting the importance of work polices for healthcare trainees.

Studies have found that experiencing psychological distress during the training stage leads to changes in career paths. ${ }^{30-32}$ These results are consistent with our finding that healthcare trainees who decided to work in non-medical fields in the future tended to have higher levels of psychological distress, compared with the trainees determined to continue on their original paths. During the COVID-19 outbreak, healthcare trainees might have been emotionally vulnerable to the crisis, because of being knowledgeable about medicine, which increased their awareness of the dangers during the outbreak's early stages. The epidemic represents an extreme situation in which being a 'doctor' is considered a demanding job with social responsibilities, which might have scared or inspired medical trainees, especially those without clinical experience. It is therefore, possible that this crisis also influenced their career choices.

\section{Limitations}

Our study has several limitations. First, given the nature of cross-sectional analyses, our data do not indicate changes in psychological distress from the pre-pandemic period; rather, they characterise the burden during the COVID-19 outbreak. Second, the response rate was low among the residents, and those who did not participate might have been the trainees with highest stress levels at work. The participation rates of undergraduate and postgraduate trainees were satisfactory $(73.22 \%$ and $71.49 \%$, respectively). Such selection is not likely to provide a thorough explanation of our findings. Third, we only measured distress symptoms once in the early phase of the outbreak. Longitudinal studies are needed in the future, as symptoms may change over time. Fourth, although the effects of age, sex, training programme and training stage were adjusted for their corresponding data analyses, residual confounding remains because data on other confounding factors were inapplicable (ie, marital status, current location, job position) or not collected (ie, socioeconomic status). Last, although the trainees came from all parts of China, our study was conducted at a single medical school and teaching hospital. The generalisability of our findings to other hospitals and medical populations remains unclear and, therefore, needs further investigation.

\section{Conclusions}

Our findings suggest that psychological distress in response to the COVID-19 outbreak is common among healthcare trainees in China. Medical trainees, particularly postgraduates and with active clinical duties, were at higher risk for psychological distress than the other groups of trainees. Stress management should be provided for high-risk healthcare trainees during the outbreak, particularly if or when the training is accelerated, and trainees join the front lines of the workforce.

\section{Author affiliations}

${ }^{1}$ Mental Health Center, West China Hospital, Sichuan University, Chengdu, China ${ }^{2}$ West China Biomedical Big Data Center, West China Hospital, Sichuan University, Chengdu, China

${ }^{3}$ Student Affairs Office, West China Hospital, Sichuan University, Chengdu, China ${ }^{4}$ Clinical Research Center for Breast Diseases, West China Hospital, Sichuan University, Chengdu, China

${ }^{5}$ Department of Medical Epidemiology and Biostatistics, Karolinska Institutet, Stockholm, Sweden

${ }^{6}$ Center of Public Health Sciences, University of Iceland, Reykjavik, Iceland

Acknowledgements The authors thank Lie Zhang (West China School of Medicine of Sichuan University, Chengdu, China) for coordinating the data collection; Fenfen Ge (West China Hospital of Sichuan University, Chengdu, China), Ting Liu (West China Hospital of Sichuan University, Chengdu, China) and Xiao Liao (Southwest University, Chongqing, China) for data collection. Mr Zhang, Miss Ge, Miss Liu and Miss Liao have no conflicts of interest to declare. We also thank the participating students at the West China School of Medicine.

Contributors WZ, DL and HS had full access to all of the data in the study and take responsibility for the integrity of the data and the accuracy of the data analysis. YW and $Y L$ contributed equally to the work. Concept and design: YW, YL, WZ. Acquisition, analysis or interpretation of data: YW, YL, HS, YF. Drafting of the manuscript: YW,

YL, HS, DL. Critical revision of the manuscript for important intellectual content: all authors. Statistical analysis: YW, JJ. Obtained funding: WZ, HS, DL. Administrative, technical or material support: WZ, HS, DL, YF. Supervision: WZ, HS, DL. All authors have contributed significantly to this work and have met the qualification of authorship.

Funding This research was supported by the National Natural Science Foundation of China (No. 81971262 to HS, No. 81801359 to DL), Swedish Research Council (No. 2018-00648 to DL), West China Hospital COVID-19 Epidemic Science and Technology Project (No. HX-2019-nCoV-014 to HS, No. HX-2019-nCoV-019 to WZ) and Sichuan University Emergency Grant (No. 2020scunCoVyingji1002 to HS, No. 2020scunCoVyingji1005 to DL).

Competing interests None declared.

Patient consent for publication Not required.

Ethics approval This study was approved by the Ethics Committee of the Sichuan University, and electronic consent forms were obtained from all participants.

Provenance and peer review Not commissioned; externally peer reviewed.

Data availability statement The data that support the findings of this study are available from the corresponding author, $\mathrm{WZ}$, on reasonable request.

Supplemental material This content has been supplied by the author(s). It has not been vetted by BMJ Publishing Group Limited (BMJ) and may not have been 
peer-reviewed. Any opinions or recommendations discussed are solely those of the author(s) and are not endorsed by BMJ. BMJ disclaims all liability and responsibility arising from any reliance placed on the content. Where the content includes any translated material, BMJ does not warrant the accuracy and reliability of the translations (including but not limited to local regulations, clinical guidelines, terminology, drug names and drug dosages), and is not responsible for any error and/or omissions arising from translation and adaptation or otherwise.

Open access This is an open access article distributed in accordance with the Creative Commons Attribution 4.0 Unported (CC BY 4.0) license, which permits others to copy, redistribute, remix, transform and build upon this work for any purpose, provided the original work is properly cited, a link to the licence is given, and indication of whether changes were made. See: https://creativecommons.org/ licenses/by/4.0/.

\section{ORCID iDs}

Donghao Lu http://orcid.org/0000-0002-4186-8661

Wei Zhang http://orcid.org/0000-0003-3113-9577

\section{REFERENCES}

1 WHO. World Health Organization: coronavirus disease (COVID-19) outbreak situation. World Health Organization, 2020.

2 Shi L, Lu Z-A, Que J-Y, et al. Prevalence of and risk factors associated with mental health symptoms among the general population in China during the coronavirus disease 2019 pandemic. JAMA Netw Open 2020;3:e2014053-e:e2014053.

3 Shechter A, Diaz F, Moise N, et al. Psychological distress, coping behaviors, and preferences for support among New York healthcare workers during the COVID-19 pandemic. Gen Hosp Psychiatry 2020;66:1-8

4 Temsah M-H, Al-Sohime F, Alamro N, et al. The psychological impact of COVID-19 pandemic on health care workers in a MERS-CoV endemic country. J Infect Public Health 2020;13:877-82.

5 Zerbini G, Ebigbo A, Reicherts P, et al. Psychosocial burden of healthcare professionals in times of COVID-19 - a survey conducted at the University Hospital Augsburg. Ger Med Sci 2020;18:Doc05Doc.

6 Lai J, Ma S, Wang Y, et al. Factors associated with mental health outcomes among health care workers exposed to coronavirus disease 2019. JAMA Netw Open 2020;3:e203976-e:e203976.

7 Chew NWS, Lee GKH, Tan BYQ, et al. A multinational, multicentre study on the psychological outcomes and associated physical symptoms amongst healthcare workers during COVID-19 outbreak. Brain Behav Immun 2020;88:559-65.

8 Representatives of the STARSurg Collaborative, EuroSurg Collaborative, and TASMAN Collaborative. Medical student involvement in the COVID-19 response. Lancet 2020;395:1254.

9 Bauchner H, Sharfstein J. A bold response to the COVID-19 pandemic: medical students, national service, and public health. JAMA 2020;323:1790-1791.

10 Health Commission of Sichuan Province C. The latest situation of new coronavirus pneumonia in Sichuan Province (released on February 7, 2020), 2020. Available: https://dwz.cn/Y1p9dhTI

11 Kang Y-kun, Guo W-jun, Xu H, et al. The 6-item Kessler psychological distress scale to survey serious mental illness among Chinese undergraduates: psychometric properties and prevalence estimate. Compr Psychiatry 2015;63:105-12.
12 Furukawa TA, Kawakami N, Saitoh M, et al. The performance of the Japanese version of the K6 and K10 in the World Mental Health Survey Japan. Int J Methods Psychiatr Res 2008;17:152-8.

13 Kessler RC, Green JG, Gruber MJ, et al. Screening for serious menta illness in the general population with the $\mathrm{K} 6$ screening scale: results from the WHO World Mental Health $(\mathrm{WMH})$ survey initiative. Int $J$ Methods Psychiatr Res 2011;20:62.

14 Wu KK, Chan KS. The development of the Chinese version of Impact of Event Scale-Revised (CIES-R). Soc Psychiatry Psychiatr Epidemiol 2003;38:94-8.

15 Lai $\mathrm{YH}$, Lee $\mathrm{YH}$, Chen YR, et al. Psychometric testing of the Impact of Event Scale-Revised (IES-R) Chinese version and current status in three major types of cancer survivors in Taiwan. Psycho-Oncology 2014;23:156.

16 Imsiragić AS, Begić D, Martić-Biocina S. Acute stress and depression 3 days after vaginal delivery-observational, comparative study. Coll Antropol 2009;33:521-7.

17 HUANG D, YIN W, ZHANG Y, et al. Effects of social and policy supports on work-family conflict in physicians. Chinese Mental Health Journal 2009;23:27-32.

18 Liu C-Y, Yang Y-Z, Zhang X-M, et al. The prevalence and influencing factors in anxiety in medical workers fighting COVID-19 in China: a cross-sectional survey. Epidemiol Infect 2020;148:e98.

19 Zhang W-R, Wang K, Yin L, et al. Mental health and psychosocial problems of medical health workers during the COVID-19 epidemic in China. Psychother Psychosom 2020;89:242-50.

20 Liu ZR, Han B, Jiang RM, et al. Mental health status of doctors and nurses during COVID-19 epidemic in China (3/4/2020). Available: http://dxdoiorg/102139/ssrn3551329

21 Dyrbye LN, Thomas MR, Shanafelt TD. Medical student distress: causes, consequences, and proposed solutions. Mayo Clinic Proceedings 2005;80:1613-22.

22 Chunming WM, Harrison R, Maclntyre R, et al. Burnout in medical students: a systematic review of experiences in Chinese medical schools. BMC Med Educ 2017;17:217.

23 Levey RE. Sources of stress for residents and recommendations for programs to assist them. Acad Med 2001;76:142-50.

24 Dyrbye LN, Thomas MR, Massie FS, et al. Burnout and suicidal ideation among U.S. medical students. Ann Intern Med 2008;149:334-41.

25 Moffat KJ, McConnachie A, Ross S, et al. First year medical student stress and coping in a problem-based learning medical curriculum. Med Educ 2004;38:482-91.

26 Stokes DC. Senior medical students in the COVID-19 response: an opportunity to be proactive. Acad Emerg Med 2020;27:343-5.

27 Services CfMM. Teaching hospitals, teaching physicians and medical residents: CMS flexibilities to fight COVID-19, 2020.

28 Sun L, Sun Z, Wu L, et al. Prevalence and risk factors of acute posttraumatic stress symptoms during the COVID-19 outbreak in Wuhan, China. medRxiv 2020.

29 Cao W, Fang Z, Hou G, et al. The psychological impact of the COVID-19 epidemic on college students in China. Psychiatry Res 2020;287:112934.

30 Melincavage SM. Student nurses' experiences of anxiety in the clinical setting. Nurse Educ Today 2011;31:785-9.

31 Hawkins M. 2017 final year medical residents survey, 2018.

32 Scharer S, Freitag A. Physicians' exodus: why medical graduates leave Austria or do not work in clinical practice. Wien Klin Wochenschr 2015;127:323-9. 